\title{
PULMONARY HYPERTENSION
}

\author{
BY \\ TERENCE EAST \\ From the Cardiological Department, King's College Hospital
}

Received May 2, 1940

This title has been chosen deliberately, although it denotes something hypothetical, as indicating a possible cause of the facts hereafter described.

These three cases were reported at the meeting of the Cardiac Society at Birmingham in 1939. The subsequent outbreak of war has made it impossible to survey the literature, so there are no references. I think, however, that the accurate presentation of the observations is the important thing. There can be no doubt that we are confronted with a curious and hitherto rare condition ; its nature and causation will need further study, but the account of these three cases may be helpful and may draw attention to others.

\section{Notes OF First CASE}

A married woman of 31, with one child aged 6, was first seen in December 1936, complaining of dyspnœa even on walking on the level. She also noticed palpitation, and had to sleep supported by three pillows, though there had been no dyspnœa at night. These symptoms had been coming on gradually for two or three years. There was no history of rheumatic fever or any important illness.

She was of medium build, with a flattish chest and a somewhat depressed lower end of the sternum. The lips were slightly cyanosed. There was no œdema, and the liver and external jugular veins were not engorged. The heart was enlarged $(15 \mathrm{~cm}$. in transverse diameter on screening). The electrocardiogram in this case (Fig. 1A), as in the others, indicated that the increase in size was in the right ventricle. Clinically, enlargement was obvious in the region of the pulmonary artery and conus arteriosus. Here one could detect definite systolic pulsation, a slight systolic murmur, a very loud pulmonary second sound, and an easily palpable closure of the pulmonary valves. Screening showed the greatly enlarged pulmonary artery (Fig. 2A) and its branches seemed conspicuous, for there was a definite " hilar dance." The lungs were clear. The left auricle was not enlarged (Fig. 2B). The peripheral arteries were normal. There was slight polycythæmia ; red cells 6.4 million,-hæmoglobin 126 per cent. There was no clubbing of the fingers. The Wassermann reaction was negative. B.P. 125/70. The enlargement of the right ventricle and of the pulmonary artery and its branches prompted a diagnosis of patent interauricular septum. 

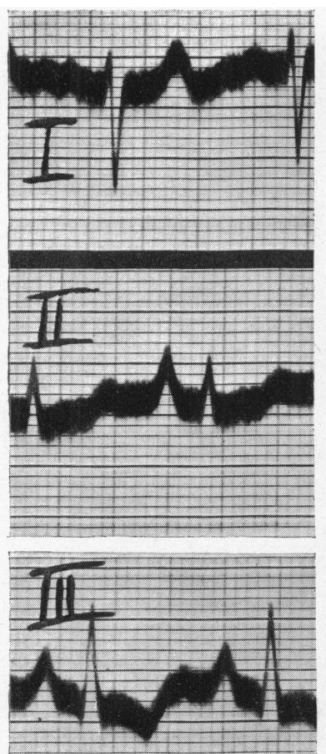

A

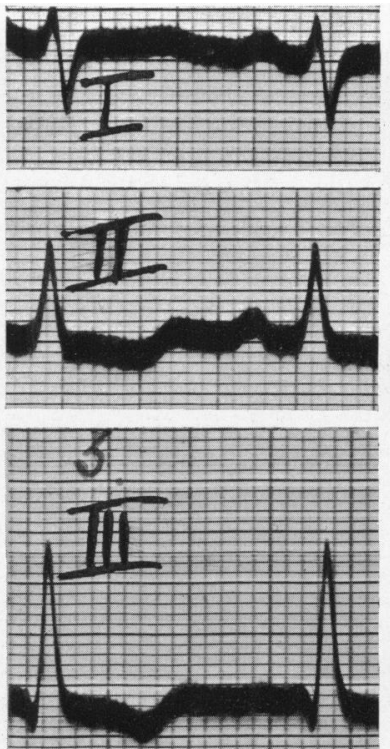

B

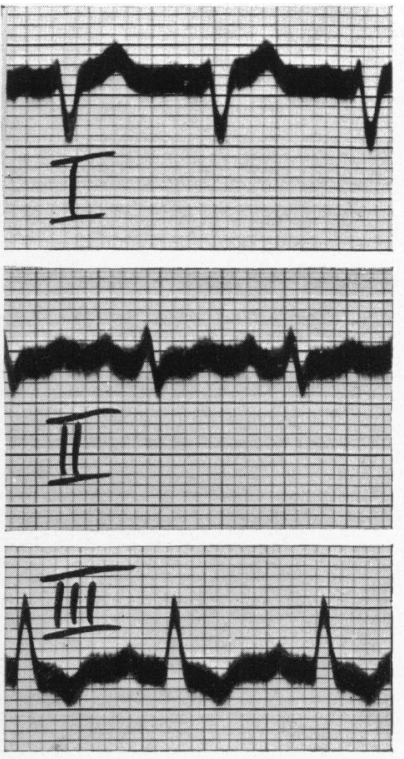

$\mathrm{C}$

Fig. 1.-Electrocardiograms showing right axis deviation. (A) Case 1, five months before death ; (B) Case 2 ; and (C) Case 3.

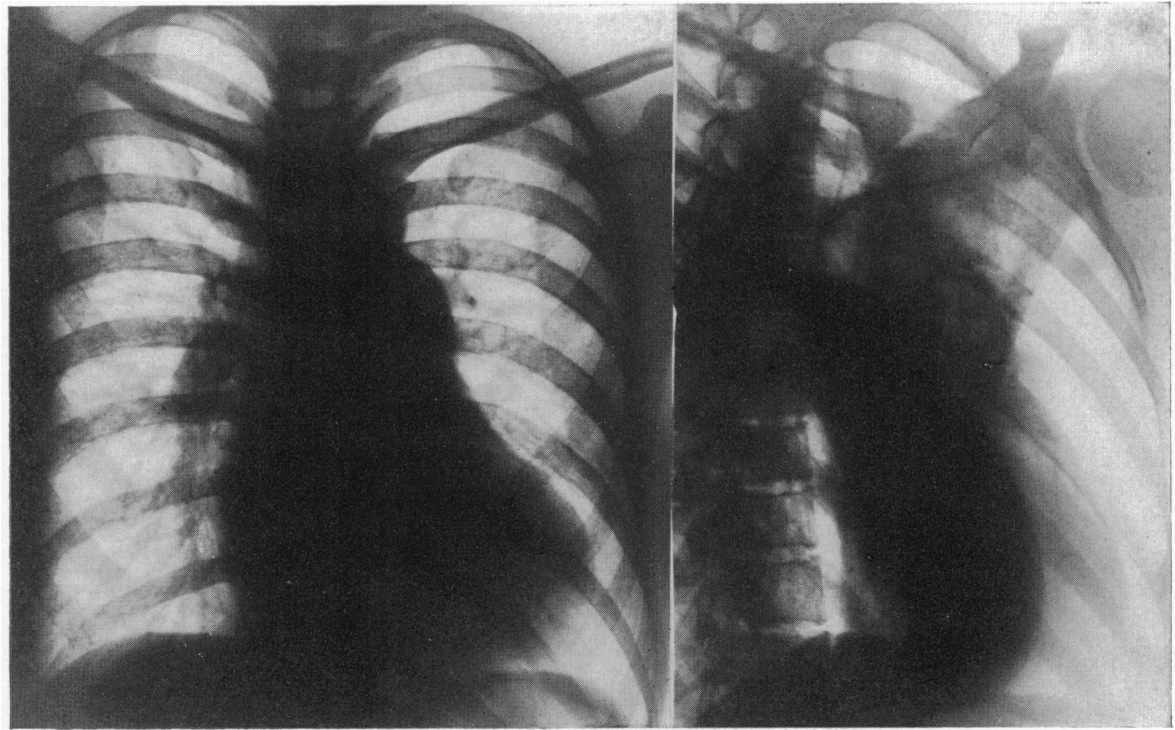

A

B

Fig. 2.-Case 1. (A) Antero-posterior view, five months before death. Note the large pulmonary artery.

(B) Right anterior oblique view. Note the normal left auricle. 


\section{Clinical Course}

In the next month signs of congestive failure of the right ventricle came on, with great enlargement of the liver, ascites, venous engorgement, and increasing cyanosis and œdema. The heart rate remained regular and between 60 and 90 , and the respiratory rate did not rise above 20 . In the last week the heart rate rose to 120 , with regular rhythm ; she became more cyanosed and drowsy, and finally died quietly without distress in May 1937.

\section{Post-Mortem Findings}

In this case the ventricles were weighed separately, after being dissected from the auricles and divided down the middle of the septum.

Heart.-Right auricle much dilated and full of post-mortem clot. Foramen ovale closed. Tricuspid valve flaps normal ; valve enlarged, admitting four fingers, the circumference being $14 \mathrm{~cm}$. Right ventricle greatly enlarged (195 g.) with huge increase in capacity, and massive musculature of the trabeculæ; the apex actually formed the apex of the heart. Wall $5 \mathrm{~mm}$. thick, two $\mathrm{cm}$. from the apex. Interventricular septum closed. Pulmonary artery large and prominent, and valves capacious and competent, the internal circumference at the top of the cusps being $90 \mathrm{~mm}$. No atheroma in pulmonary artery or its branches and no macroscopic abnormality in smaller twigs. Left auricle small with normal thickness of wall ; mitral valve admitted three fingers, the circumference of the ring being $10 \mathrm{~cm}$. ; slight thickening of the anterior cusp. Left ventricle of normal size, weighing when separated $135 \mathrm{~g}$. ; thickness of the wall, two $\mathrm{cm}$. from the apex, $7.0 \mathrm{~mm}$.

Myocardium throughout looked healthy, with good colour and resilience ; microscopical sections showed fibres of the right ventricle hypertrophied. Coronary arteries, normal.

Lungs.-These were a little collapsed at the bases from upward pressure by the abdomen distended by ascites. There was no emphysema or brown induration and they were remarkably free from œdema and engorgement; no sections were made of the lungs. Elsewhere, the usual changes due to severe and longstanding venous engorgement.

\section{Summary}

In this case the outstanding finding was the gross hypertrophy of the right ventricle and enlargement of the pulmonary artery, for which no cause was apparent to the naked eye. The state of the lungs and of the left auricle would exclude any cause affecting them from the left side. The findings confirmed the clinical observations, but not the suggested cause ; nor did they point to another.

\section{Notes of Second CASE}

A married woman of 24 , pale and without cyanosis, seen in the autumn of 1938; she gave a history of several attacks of right ventricular failure in the last six years. During the last year she had been more or less an invalid and three 
months ago her abdomen had twice been tapped for ascites. She said she had never had rheumatism. The feet were slightly swollen. The liver was enlarged and soft and a little tender. The external jugular veins were not distended, but filled on pressing on the abdomen.

Clinically, the right ventricle was much enlarged. This was confirmed by the cardiogram (Fig. 1B) and by the skiagram (Fig. 3). There was systolic

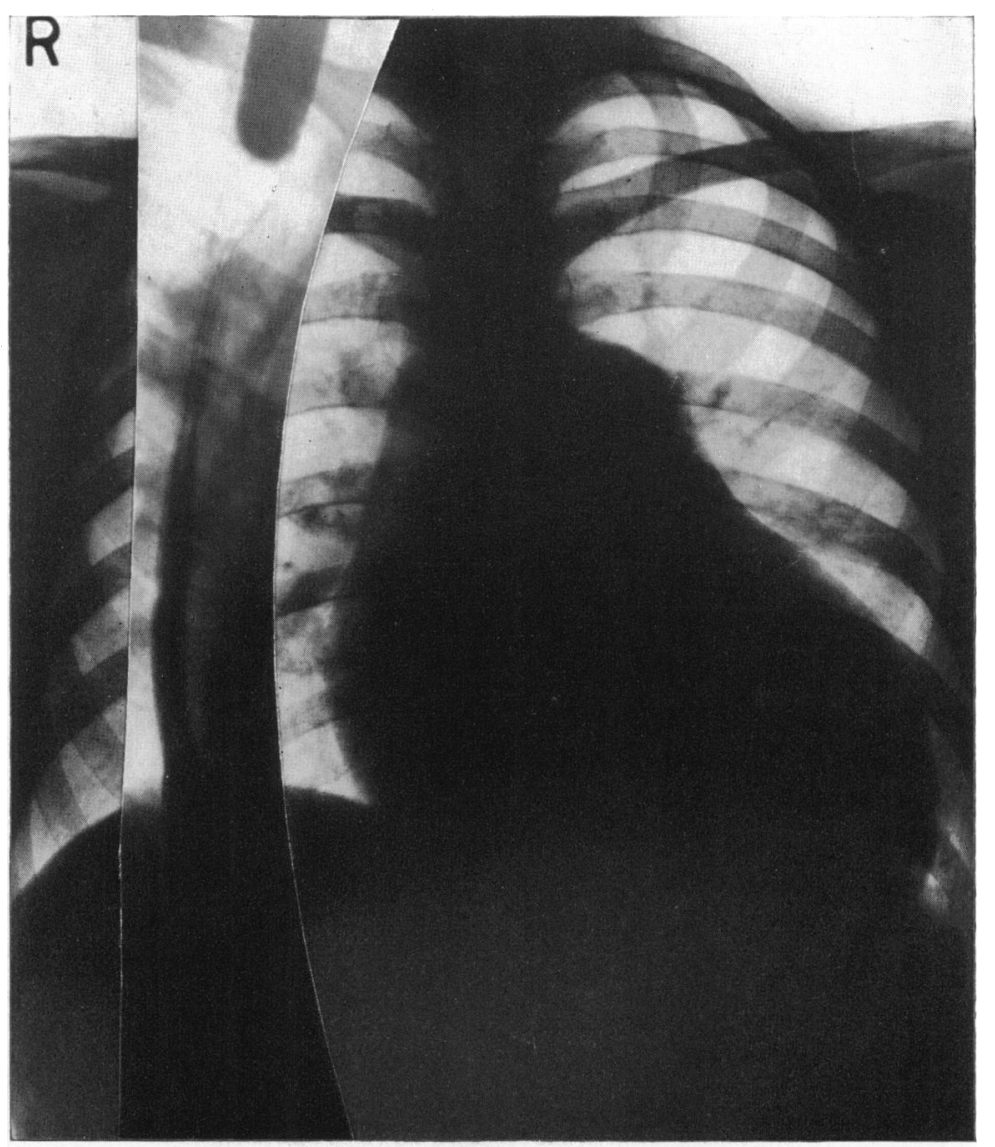

Fig. 3.-Case 2. Antero-posterior view, three weeks before death. Note large pulmonary artery.

The right anterior oblique view, with barium in the œesophagus to show the absence of enlargement of the left auricle, has been superimposed in the space between the right border of the heart and the right chest wall.

pulsation in the pulmonary area, with palpable closure of the pulmonary valves and a very loud pulmonary second sound. The left auricle was normal in the oblique view (Fig. 3). There was a slight local systolic murmur at the apex.

Respiration was easy and quiet at 20 per minute, and the lungs were clear. The heart rhythm was regular, with a rate of 90 . B.P. 118/78. Slight albuminuria. 


\section{Clinical Course}

Under treatment she improved so much that she was ready to go home. The day before, she suddenly became drowsy and the abdomen filled up ; the next day she was collapsed, pale, and cyanosed, with transient auricular fibrillation ; a few crepitations appeared at the bases, the pulse became imperceptible, with but little increase in the rate of respiration ; and in a few hours she was dead.

\section{Post-Mortem Findings}

Heart.-Slight increase of fluid in the pericardial sac. Total weight $425 \mathrm{~g}$. Right auricle much distended. Right ventricle very large $(210 \mathrm{~g}$.) with massive walls and thick trabeculæ. Tricuspid valve, normal flaps, with large orifice, admitting four to five fingers. Pulmonary valves large and competent ; pulmonary artery large, with internal circumference just above the cusps of $90 \mathrm{~mm}$. Several small oval atheromatous patches, 3-5 $\mathrm{mm}$. long, near the bifurcation, with smaller ones in the first main branches. Left auricle normal in capacity and thickness of walls.

Mitral valve, slight thickening of posterior cusp due to old rheumatic carditis ; orifice admitting two fingers. Left ventricle small, with normal walls (weight 131 g.). Coronary arteries normal. Myocardium rather pale, but resilient. Ductus closed and septa whole. Aorta and aortic valves normal. Aorta $70 \mathrm{~mm}$. in internal circumference at the valves.

Lungs.-L., 375 g. ; R., 415 g. A little ædema of the right upper lobe and some congestion of the right lower lobe. Bronchioles rather red, with a little muco-pus. On the whole, very free from congestion and œdema, and without brown induration.

There were the usual changes due to chronic congestion in the liver, kidneys, and spleen, with much ascites and some œdema.

\section{Microscopical Findings}

Section of the myocardium showed hypertrophy of the fibres of the right ventricle (Fig. 4). The lungs showed some catarrhal cells in the alveoli. The muscle coats of the arterioles were perhaps a little hypertrophied (Fig. 5). There was no proliferation of the intima or obliteration of the lumen to be seen.

\section{Summary}

In this case again there was, at the end, great hypertrophy of the right ventricle, with enlargement of the pulmonary artery. No structural changes were to be detected as a cause. The clinical course was rather long, with recurrent attacks of failure of the right ventricle. As in the first case, the slight degree of dyspnœa was worth noting. The rhythm remained regular, apart from one short bout of fibrillation, which was probably a result rather than a cause of failure. The final failure was sudden and rapid. 

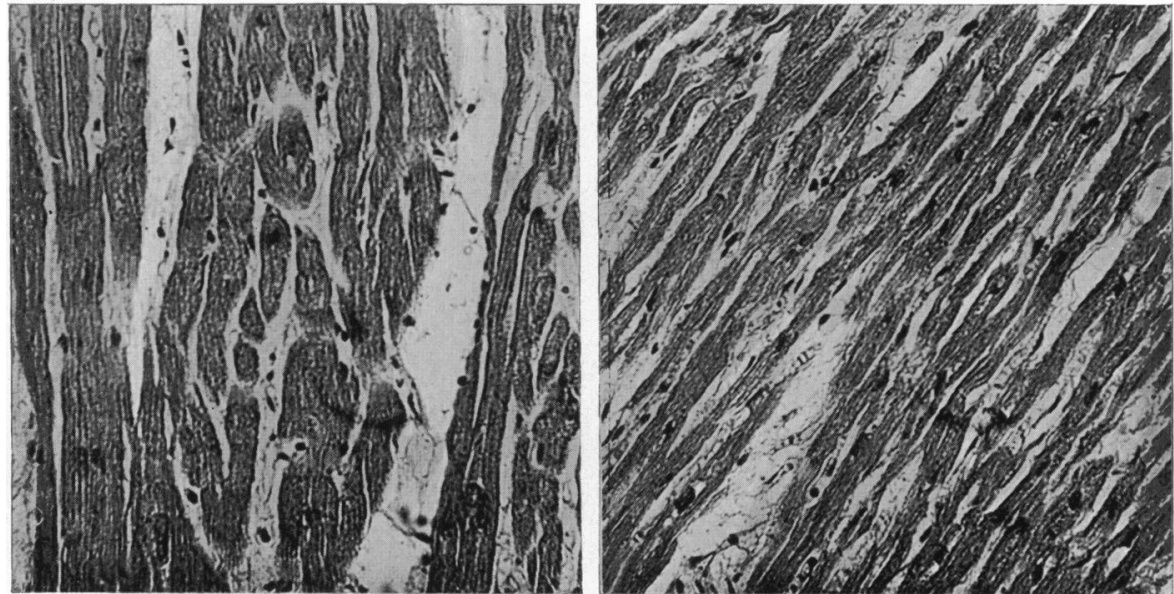

FIG. 4.-Case 2. (A) Section of right ventricle showing hypertrophy ; (B) Section of left ventricle for comparison. Magnification $\times 180$.

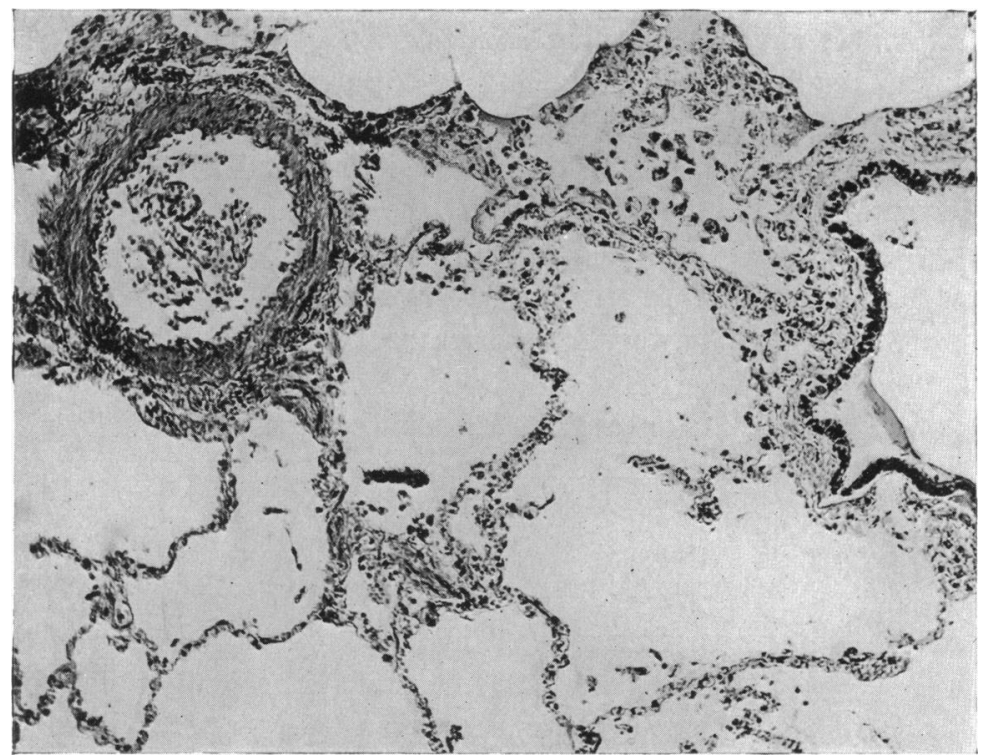

FIG. 5.-Case 2. Pulmonary arteriole, showing perhaps some hypertrophy. Magnification $\times 120$.

\section{NOTES OF THIRD CASE}

A married woman of 31 , who came into hospital early in 1939. During the summer before she had begun to notice undue dyspnœa and distress when playing tennis. There was no history of rheumatism. She had had a miscarriage with a hydatidiform mole five weeks previously. There had been increasing dyspnœa on exertion for some months, becoming much worse since the miscarriage. Edema of the feet had appeared within the last few days. She had had no cough, nausea, or vomiting. 
The hands and feet were cold and blue ; the lips, cheeks, and ears were blue. The legs were odematous and there was a sacral pad. The liver was a little enlarged, and there was some congestion of the external jugular veins. The lungs were clear and there were no rales ; respiration was easy, without any cough or distress, at 20 to 24 per minute. She could lie flat without discomfort ; and was rather quiet and apathetic.

The heart showed an increase of the right ventricular thrust, with systolic pulsation in the pulmonary area. The closure of the pulmonary valves was palpable, and the pulmonary second sound was very loud. Gallop rhythm was audible near the left edge of the sternum. There were no murmurs. The pulse was regular and very weak, with a rate of 115 . No blood pressure reading could be obtained. The urine contained much albumen. The blood urea was $90 \mathrm{mg}$. per c.c. The cardiogram confirmed the gross enlargement of the right ventricle (Fig. 1C). A skiagram (Fig. 6) showed the great heart shadow, with prominence of the pulmonary artery.

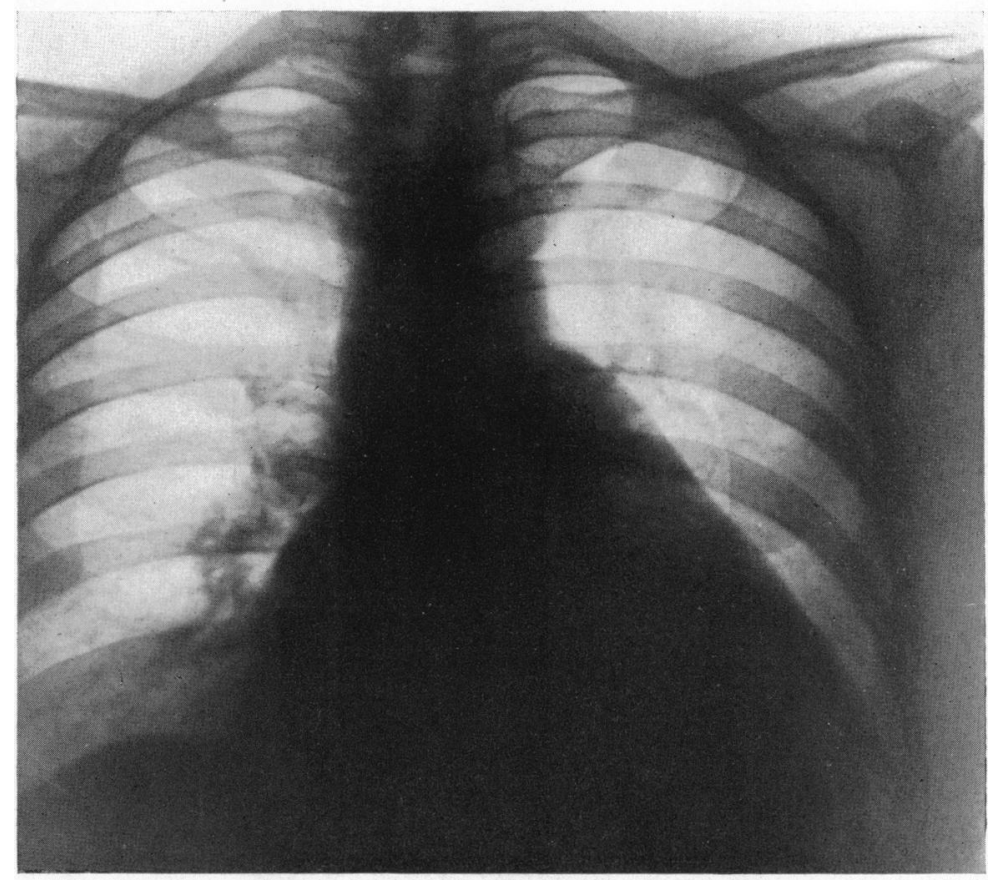

FIG. 6.-Case 3. Antrro-posterior radiogram, 24 hours before death. (Taken in bed.)

\section{Clinical Course}

During the next twenty-four hours she rapidly became worse. Drowsiness came on and she tended to slip down ; in fact, she lay flat with no inconvenience or dyspnœa ; the breathing was regular and the rate did not rise above 24 until just before the end. The cyanosis increased, and the jugular veins became more distended. Venesection was ineffectual, for only an ounce or two of very thick, 
dark blood could be obtained. The heart rate increased to 140 , with regular rhythm ; drowsiness increased to coma, and she died in a few hours.

I would comment now upon the clinical picture of pure right ventricular failure. Usually one sees it secondary to failure of the left side, or the case is one of mitral disease with embarrassment of the pulmonary circulation ; or there is pulmonary disease, such as emphysema or bronchitis. Here, all the points were clear and uncomplicated. One was struck by the absence of dyspnœa. The veins filled up, the liver became more engorged, and the cyanosis increased, but the pulmonary circulation remained free from difficulties, so that the breathing continued easy until the patient was nearly dead. It is rare in my experience to witness such a pure and rapidly progressive failure of the right ventricle. What one saw bore out fully the modern theory that cardiac dyspnœa is the result of engorgement of the pulmonary circulation.

\section{Post-Mortem Findings}

A well-nourished woman, with œdema of the legs, chest, and abdominal wall, and with intense cyanosis of face, ears, and fingers.

Heart.-Weight 372 g. Right auricle and great veins very engorged. Tricuspid valve enlarged, taking four fingers. Right ventricle very capacious, with massive hypertrophy of its walls, and huge trabeculæ (weight 180 g.) : muscle firm and resilient and of good colour. Pulmonary valves large and competent. Pulmonary artery large, with an internal circumference just above the cusps of $85 \mathrm{~mm}$. (normal, about $66.5 \mathrm{~mm}$.) ; slight atheroma in small flecks and spots. Left auricle of normal capacity and thickness, mitral valve taking two fingers ; very slight thickening at the edge of the cusps. Left ventricle of normal size and capacity (weight 112 g.) Aortic valves normal ; also aorta, coronary arteries, cardiac septa, and ductus arteriosus.

Lungs.-Right lung 465 g. (15 oz.). Slight collapse at extreme base posteriorly. No œdema, engorgement, or induration. A little muco-pus in the bronchioles. Right pleural sac, 300 c.c. clear fluid.

Left lung, 445 g. (14 oz.) ; slight œdema at the extreme base ; no induration or engorgement. Both lungs were, in fact, remarkably light and dry and free from engorgement or œdema.

The liver showed pronounced nutmeg changes; there was some ascites and congestion of the spleen. The kidneys were rather small, with slight patchy scarring, scattered irregularly on the surface, and affecting the cortex but little underneath it.

\section{Microscopical Findings}

The fibres of the right ventricle were hypertrophied (Fig. 7), but no disease of the myocardium was found. In the lungs the tissue itself was free from disease. The muscular coats of the smaller arterioles were perhaps a little thickened. Here and there a few of the smallest arterioles were partly obliterated by proliferation of the intima, but this was not a common finding (Fig. 8A). 
A few of the larger arterioles showed crescentic patches of intimal proliferation, with some vacuolar degeneration (Fig. 8B).

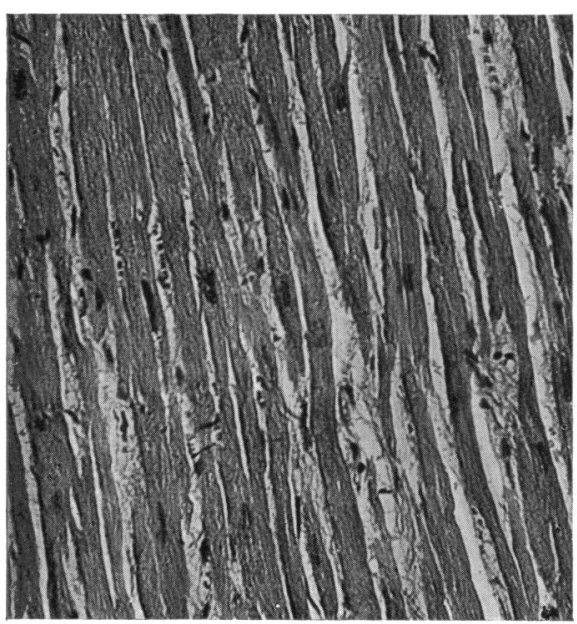

A

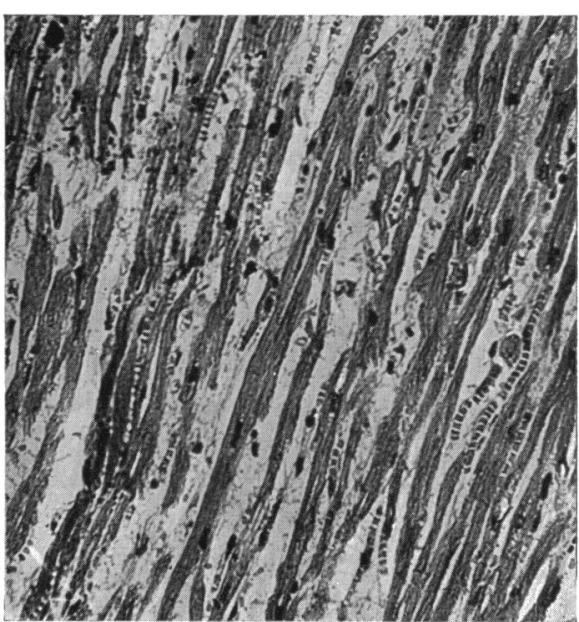

B

Fig. 7.-Case 3. (A) Section of right ventricle showing hypertrophy ; and (B) section of left ventricle for comparison. Magnification $\times 180$.

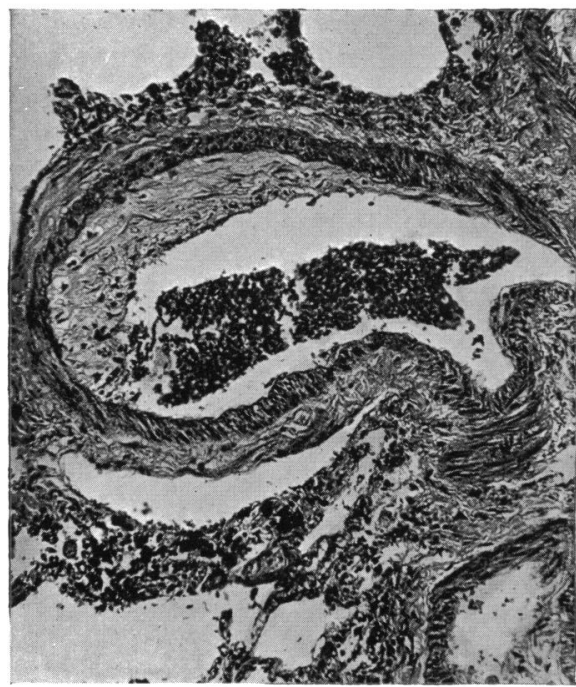

A

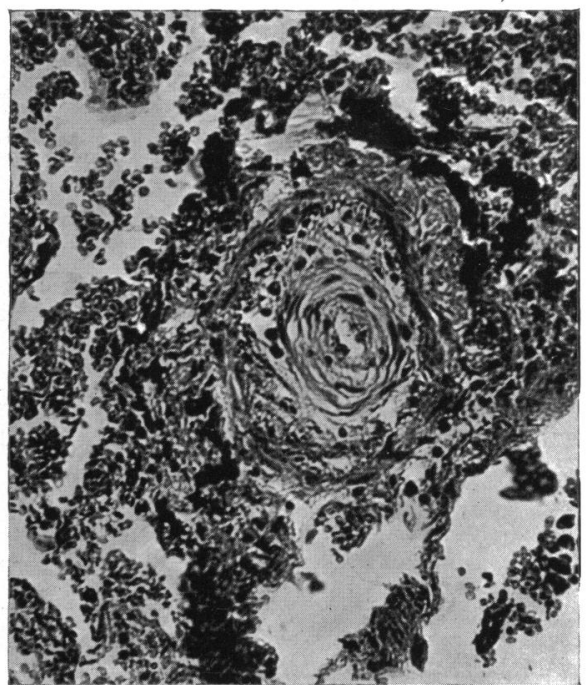

$\mathrm{B}$

Fig. 8.-Case 3. Arteriole in lung. (A) Magnification $\times 100$; and (B) Magnification $\times 200$.

\section{Summary}

This patient died of pure right ventricular failure which progressed rapidly towards the end. The autopsy showed great hypertrophy of the right ventricle, 
and some increase in the size of the pulmonary artery. Some pulmonary arterioles showed an obliterative process. The lungs were free from disease, congestion, or œdema.

\section{Summary OF Autopsy Findings}

This is a summary of certain measurements of the hearts of these three cases. The normal figures are taken from Vierordt's well-known " Tabellen " for persons of similar age and sex.

TABLE I

Weight of THE Right and Left Ventricles

\begin{tabular}{|c|c|c|c|c|}
\hline & \multicolumn{4}{|c|}{ Weight in Grammes } \\
\hline & $\begin{array}{c}\text { Normal } \\
\text { (Vierordt) }\end{array}$ & Case 1 & Case 2 & Case 3 \\
\hline 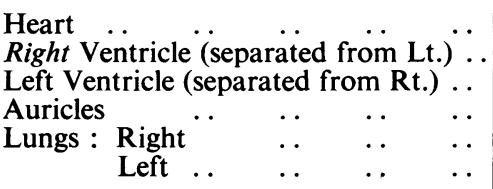 & $\begin{array}{r}250 \\
59 \\
120 \\
85 \\
500 \\
425\end{array}$ & $\begin{array}{r}415 \\
195 \\
135 \\
85 \\
- \\
-\end{array}$ & $\begin{array}{r}391 \\
210 \\
101 \\
80 \\
415 \\
375\end{array}$ & $\begin{array}{r}372 \\
180 \\
112 \\
80 \\
465 \\
445\end{array}$ \\
\hline
\end{tabular}

The great increase in the weight of the heart was due to the increase in the bulk of their right ventricles : whereas the left ventricle is about twice the weight of the right, here in one case the right ventricle was twice the weight of the left ; in the others it was 50 per cent heavier.

The photomicrographs and cardiograms agreed with the diagnosis of hypertrophy.

The weights of the lungs confirmed their normal appearance and the absence of œdema or engorgement.

Table II shows the measurements of the internal circumference of the pulmonary arteries and aortas of these cases, taken just above the valves, and compared with Vierordt's normals :

TABLE II

A Comparison of the Size of the Aorta and of the Pulmonary Artery in these CASES AND IN NORMALS

\begin{tabular}{|c|c|c|c|c|c|c|c|}
\hline & & & & \multicolumn{4}{|c|}{ Internal Circumference in Millimetres } \\
\hline & & & & $\begin{array}{l}\text { Normal } \\
\text { (Vierordt) }\end{array}$ & Case 1 & Case 2 & Case 3 \\
\hline Aorta .. & - & . & $\cdots$ & $55-79$ (range) & 68 & 70 & 60 \\
\hline Pulmonary artery & $\ldots$ & $\ldots$ & . & $66 \cdot 5$ (average) & 90 & 90 & 85 \\
\hline
\end{tabular}


These measurements after death confirm the suggestion of enlargement of the pulmonary artery which one gained during life, clinically and by the skiagram.

\section{Discussion}

It remains to produce some explanation for the findings in these three young women. I think that the cases are similar : the age and the clinical course in each case are much alike. To explain pure failure of a greatly hypertrophied ventricle is the problem.

The enlargement of the pulmonary artery must be explained. It might be caused by increase of the blood entering it, as in thyrotoxicosis or as in the patent septa or patent ductus arteriosus ; but those defects were wanting. Increase in the pressure above the valves would also cause it, as in severe mitral stenosis or in some cases of emphysema or with extensive obliteration of the pulmonary arteriolar bed.

The slight thickening of the mitral flaps can have had no effect on the right ventricle ; particularly with the normal appearance of the left auricles before and after death.

There was no disease of the lung tissues.

In one case the pulmonary arterioles showed some degree of obliteration here and there, but it is hard to believe this was extensive enough to affect the right ventricle. The other case showed no change in the pulmonary vessels, but the right ventricle was just as large. Of the third the lungs were not sectioned. The flecks of atheroma were such as one sees often enough in the pulmonary artery in mitral stenosis or in some cases of emphysema when the tension in the artery has been high ; but it may be found when no increase in tension may be supposed to have existed. It seems possible that the changes, atheromatous and obliterative, found in the pulmonary arteries and arterioles in those cases may be the result of high pressure in the pulmonary circuit.

\section{SUMMARY}

Three cases are described in which failure of a conspicuously hypertrophied right ventricle took place. At autopsy no satisfactory cause for this hypertrophy could be found.

They present a clinical picture which should be fairly easily recognizable during life.

1. Enlargement of the right ventricle, with the characteristic electrocardiogram.

2. Enlargement of the pulmonary artery, confirmed by the skiagram.

3. A loud pulmonary second sound suggesting a high pressure in it.

4. Intractable and progressive failure of the right ventricle, with the maintenance of normal rhythm, dyspnœa of any severity being absent.

5. A normal appearance of the left auricle. 
6. An absence of valvular defects, congenital or acquired, or of patent septa. (Patent interauricular septum might be difficult to exclude.)

7. An absence of pulmonary disease.

8. The absence of evidence of syphilis.

It is suggested that a condition of idiopathic or essential pulmonary hypertension may exist as a cause for those findings. 